Please NOTE: This is a pre-proof accepted version. The permanent link for the published article is https://doi.org/10.1177/14687941211018043

Please cite as: Adams M, Ormrod J, Smith S. (2021) Notes from a field: a qualitative exploration of human-animal relations in a volunteer shepherding project. Qualitative Research. Online First, May 2021. doi:10.1177/14687941211018043

\title{
Notes from a field: A qualitative exploration of human-animal relations in a volunteer shepherding project
}

Matthew Adams ${ }^{1}$, James Ormrod and Sarah Smith

University of Brighton, UK

\begin{abstract}
There is a burgeoning interest in human-animal relations across the social sciences and humanities, accompanied by an acceptance that nonhuman animals are active participants in countless social relations, worthy of serious and considered empirical exploration. This article, the first of its kind as far as the authors are aware, reports on an ongoing qualitative exploration of an example of contemporary human-animal interaction on the fringes of a British city: volunteer shepherding ('lookering'). Participants are part of a conservation grazing scheme, a growing phenomenon in recent years that relies on increasingly popular volunteer programmes. The primary volunteer role in such schemes is to spend time outdoors checking the welfare of livestock. The first section of the article summarises developments in more-thanhuman and multispecies research methodologies, and how the challenges of exploring the non- and more-than-human in particular are being addressed. In the second section, we frame our own approach to a human-animal relation against this emerging literature and detail the practicalities of the methods we used. The third section details some of our findings specifically in terms of what was derived from the peculiarities of our method. A final discussion offers a reflection on some of the methodological and ethical implications of our research, in terms of the question of who benefits and how from this specific instance of human-animal relations, and for the development of methods attuned to human-animal and multispecies relations more generally.
\end{abstract}

\section{Keywords}

Sheep, shepherding, human-animal studies, multispecies, conservation, volunteering, more-than-human, animal-assisted intervention

\footnotetext{
${ }^{1}$ Corresponding author: Matthew Adams, School of Humanities and Applied Social Science, University of Brighton, Falmer, Brighton, BN1 9PH, UK. Email: Matthew.adams@brighton.ac.uk
} 
Notes from a field 


\section{Introduction}

In this article we share findings from our qualitative study of a volunteer shepherding programme. An important conservation strategy across Europe in recent years has been the reintroduction of grazing and browsing animals (such as horses, cattle, deer, goats and sheep) better maintain biodiversity in habitats such as grassland and healthland. The volunteer role in such ventures comprises spending time outdoors checking the welfare of livestock. It is variously referred to as 'urban shepherding' as many of these schemes take place on urban fringes and largely attract volunteers from urban areas - or 'lookering' - which marks a distinction with shepherding in that volunteers rarely 'herd' the animals but observe and report on their well-being. Despite some interest in human-sheep encounters (e.g. Despret and Meuret, 2016; Gray, 2014), there have been no studies, to our knowledge, of the human-sheep encounter at the heart of this burgeoning phenomenon. The ongoing project we chronicle here is an attempt to address this gap, via the study of a volunteer lookering programme on the South Downs, an example of schemes rapidly growing in popularity in the UK and Europe.

In what follows we recount how we have grappled with the human-animal dimension of our project to date and offer some critical reflections on how we might best go about doing justice to the multi-species relationships involved. In the first section of the article, we offer an account of the methodological challenges faced by the qualitative study of human-animal interaction; and in the second explain how we have attempted to navigate them, emphasising the practicalities of the methods we used. In the third section we offer a brief overview of some of our key findings to date. Finally, we reflect on some of the wider methodological and ethical implications of our research for the development of methods attuned to human-animal and multispecies relations.

\section{The animal turn as methodological challenge}

Across numerous disciplines including the humanities, biological and social sciences, theory and research increasingly addresses the relations between human and other forms of life, diversely conceptualised as human-nature connections, humannonhuman relations, human and more-than-human worlds, posthumanism and much more besides: a 'new nexus of interdisciplinary scholarly interest in the humananimal relationship' (Andersson Cederholm et al. 2014, p. 5; e.g. Åsberg, 2018; Haraway, 2016; Lloro-Bidart, 2018; McLeod, 2014). ${ }^{1}$ In parallel, empirical researchers across numerous disciplines have begun to make efforts to pay attention to entanglements between non-humans and humans, and meet the ethical and methodological challenge of 'speaking with and for nonhuman others' (Åsberg, 2018), across the many texts, sites, practices and events marked by human-animal and multispecies relations (Swanson, 2017; 2019). 
Dowling et al. (2017) review how qualitative researchers in human geography have explored and refined more-than-human research methodologies to date, but their framework reflects multispecies methodologies across the disciplines more broadly. They distinguish between conventional, innovative and human-more-than-human collaborative methodological approaches. Their delineation of 'conventional approaches' includes conceptual and historical analyses, focus groups and interviews (e.g. Maurstad, Davis and Cowles, 2013). 'Innovative approaches' involve developing forms of attentiveness and experimentation that share the aim of 'giving voice to more-than-humans' more fully (p. 825; c.f. Van Doreen et al., 2016), including versions of ethnography explicitly attuned to nonhuman agency and encounters between multiple species (e.g., Fuentes, 2010; Taylor and Pancini-Ketchabaw, 2015). Sometimes explicitly referred to as multispecies ethnography. A commitment to sustained observation attuned to bodily cues and alive to animals and other species as active agents in their own right reflects the emergence of multispecies ethnography as a distinct approach (e.g. Coulter, 2018; Hamilton and Taylor, 2017; Maurstad, Davis, \& Cowles, 2013; Ogden, Hall, \& Tanita, 2013).

Also included in this category are related approaches that directly inform our own 'knowing through showing' and 'walking while talking' (Dowling et al. 2017, p. 825). Walking while talking 'prompts talk rich in spatial knowledge' - and is attuned to the liveliness of the landscape, including encounters with other species as a basis for conversation (Hitchings and Jones, 2004). In 'knowing through showing', the 'researcher as novice is inducted into knowledge by expert guides who show them around their worlds, (Pitt, 2015 p. 48), and might also involve dialogue through nonverbal gestures, incitements to touch, look, listen or smell further. In this way, research participants' established capacities to feel and respond to cues in the landscape (as 'experts') are shared and reflected upon. In terms of human-animal relations more specifically, Pitt, building on Ingold (2000), claims that 'by following experts' signals, a researcher becomes more sensitive to nonhumans in the environment' (p. 48). Being shown around a world obviously incorporates the possibility of walking and talking, hence these two methodological innovations are closely connected. We return to both in relation to our own project below.

Dowling et al.'s third category emphasises attempts at human-more-than-human collaboration. Creative efforts to do just this to date include interdisciplinary collaborations between the natural and social sciences (Taylor and Hamilton, 2014; see also Locke and Keil, 2015). Attempts to emphasise the agency of place are also considered as an important theme in experimental, collaborative, more-than-human methodologies. This approach strives to pay closer attention to the ways in which the agency of nonhuman entities "saturates our research interactions" (Wright et al., 2012 p. 52). Here developing methodologies involves place-based alliances with indigenous practitioners to generate relational narratives of human and more-than- 
human "emergent belonging" (Wright, 2015); and attempts to collaboratively respond to longstanding 'Indigenous assertions of sentient, genealogied landscapes' (Coombes et al. 2014, p. 850). Bastian et al. (2017) open up a number of future directions that such a methodology might take, under the banner of 'more-thanhuman participatory research' (see also Alam, McGregor and Houston, 2018; Coombes, Johnson and Howitt, 2014).

As the merits of the different methodologies described above and more are increasingly debated (e.g. Gillespie, 2019; Hamilton and Taylor, 2017; Heddon, 2017; Ogden et al. 2013; Smart, 2014), there remains a general need to explore the viability of a broader range of qualitative methods for addressing human-animal and multispecies relations (Swanson, 2017; 2019). We now turn our attention to our own methodology, which we locate, following Dowling et al's typology, between the conventional and the innovative.

\section{Methodology: Between the conventional and the innovative}

The decision to study lookering was influenced by a shared interest in human-animal and multi-species relations, and a desire to explore it empirically, especially in relatively neglected urban and semi-urban settings (Arcari et al. 2020). We were motivated by an epistemological commitment to qualitative research, and by a theoretical and ethical commitment to attend to human-animal relations in a particular setting as relations, and in doing so to try to find ways, in the research process, to make nonhuman animals 'matters of concern' or care rather than 'matters of fact' (de La Bellacasa, 2011). At its simplest our intention, to paraphrase Pitt on plant life, was not to speak for sheep, but to research with sheep as more prominent agents (2015, p. 48). At the same time, we adopted the more familiar qualitative research goals of exploring the meanings and perceptions our human participants derived from the practice of lookering.

Out of these general objectives we formulated the following research questions: 1) How is lookering experienced and made sense of by those directly participating in it? 2) How do participants understand and relate to the sheep and their physical presence? 3) Who benefits from lookering and how? The method we adopted was an interview-led combination of 'walking and talking' and 'knowing and showing', falling somewhere between the 'conventional' and the 'innovative' in Dowling et al's categorisation as described above. There was a clear practical dimension for this decision - the practice of lookering involves walking, and we decided a 'go-along', or more specifically, 'walk-along' interview approach was important for us in grounding the lookering experience in time, space and place (Castrodale, 2017; Springgay and Truman, 2017). We designed interview questions that were open whilst lending themselves to lookerer's knowledge of the sheep, landscape and lookering practice 
as we walked, thereby facilitating 'knowing and showing' where appropriate (e.g., 'What normally happens on a shift?'; 'What have you noticed about the sheep?').

As we initially lacked necessary species-specific knowledge of sheep, the lead author also undertook a literature review and developed a historical analysis of sheep and human-sheep relations as a vital component of the research - an application of what Dowling et al (2019) categorise as conventional methodologies (Adams, 2020). The knowledge produced would have benefitted from additional disciplinary inputs, not least zoology or ethology, a point that applies to the project more generally, and made in relation to other human-animal studies (e.g., Locke and Keil 2015).

Nonetheless for us this effort was another important step in situating our knowledge of sheep life on the site and in the meso- and macro-contexts that extend beyond the place in which we encounter them (Shapiro, 1990). This provided a helpful if asymmetrical parallel to the biographical information revealed by our human participants in the course of most interviews; and in doing so allowed us to more comprehensively make sheep 'matters of concern'.

In practice, we first recruited the ranger employed by the local council to co-ordinate and oversee the volunteer programme in the area as a gatekeeper. Through him we then recruited lookerers ( $n=18$ ) who were willing to be interviewed as they performed their volunteering duties - commonly referred to as a 'shift'. A shift can take anywhere between 30 and 90 minutes, duties including checking on the welfare of the grazing sheep in a specified area (one or more enclosed fields), inspecting fences, water troughs, gates, signage and so on, and talking with members of the public (walking dogs, rambling etc.). On the day of an interview, we arranged to meet participants just prior the beginning of the shift, and then accompany them as they 'looker', asking our open-ended interview questions as we walked.

Our thematic analysis entailed listening back over the audio recordings, transcribing interviews and subsequently developing codes, intuitively and individually at first. We then shared codes and together discerned emerging themes inductively, returning to the transcripts to develop and delineate them before further discussion, and finally settling on a number of salient themes. In the process of analysis, we identified multiple themes, also deductively informed by the animal turn described above. Our themes included participants' wellbeing and nature connection; a sense of guardianship; the character of sheep; and birth and death. In the next section, we offer a brief overview of our analysis primarily in response to the third of our research questions - who benefits from lookering and how? In the context of a Research Note, we opt for this specific focus to illustrate the specific value of our methods. 


\section{Who benefits and how?}

Lookering was experienced and understood by our human participants primarily as beneficial in terms of a sense of positive connection to the landscape in general and the sheep in particular. This was revealed in relatively explicit and direct affirmations of these benefits but was also an integral subtext in the act of walking talking, knowing and showing. The first question asked of participants was along the lines of 'What happens on a shift, what is generally involved'. As we then walked, it would often be a good few minutes before another question was asked, as 'things' broadly related to this question cropped up, because, of course, a shift was happening. In one interview with Bea, by no means exemplary, the interviewer only interjects with one or two words for twenty-odd exchanges after that first question, before this:

B: and can you hear you may be able to hear a skylark [yea] there's skylarks all over here

I: yea I can see one

$\mathrm{J}$ : there's loads of them they go up singing singing sing all day it's nice to again if it's nice for them it's [...] it's perfect for them to settle into. We have pheasants sometimes walking through, I saw one the other day. We have hawks, kestrel, things like that come hovering overlooking for little bits of wildlife. It's really nice to on any day really I don't mind even when it's wet or windy or nasty there's always something to see or do [...] sheep behaviour's interesting

Here the sense of joy is tangible, a shift of emphasis prompted by the sound of a skylark. Walking and having a job to do somehow allows the conversation to hop about from topic to topic much more than it would seated indoors, perhaps a response to the relative interpersonal freedom afforded of being side by side, whilst being stimulated by the affordances offered up by the life of the landscape.

At other times, a positive sense care, purpose and duty - what we refer to as guardianship - is articulated as a powerful benefit of lookering. Participants regularly spoke of how a sense of responsibility for the welfare of the sheep was experienced as both a 'push' - ensuring they always fulfilled a shift they had signed up for: 'you've got your duty to like protect the sheep be sure they're alright' (Kerry); 'I feel duty bound to get them all up if I can see them sitting down' (Simon); and a 'pull' - the reward of feeling needed, and doing something worthwhile.: 'I think that sense of meaning and purpose is what motivates me to do it' (lan). In our interview with Stephen as his shift drew to a close, he wanted to say one more thing before we stopped recording:

I'd say that in any one day and that includes today lookering is the best it's generally the best thing I do all day. It's generally the best thing I do all day. It really is you 
know it's you know whatever mood I I am in when I get up here you know, firstly I've got to tend to the sheep so there's something to look after you know which is really good that needs my help and that's good yea l'd say l'd say that that it's the best thing that I do all do it really is.

It is worth noting that the importance of a sense of purposefulness was commonly expressed in caring for the sheep but also for the wider goal of conservation grazing. Most participants articulated this dimension as an important motivation for volunteering.

As a human-animal relationship, we were not interested only in the benefits of lookering for humans, but for sheep too (and at least potentially, others). Helpful here is Gorman's (2019) conceptualization of a version of human-animal relations 'animal-assisted interventions' - precisely in terms of who they produce benefit for. He places parasitic relations at one pole (benefit humans at the expense of animals), and mutualistic at the other (produce some form of benefit to humans and animals alike), with commensal relations (benefit humans in ways that do not impact on animals) holding the centre. If we were approaching lookering as an animal-assisted intervention (not too fanciful considering the positive benefits for participants described above), it clearly does not resemble the kind of embodied, tactile, interactions we might expect to see in canine-assisted therapy, or even in a cat café (Robinson, 2019). As sheep do not appear to have the capacity or inclination to interact with humans in embodied or tactile way, we might be tempted to locate lookering squarely within commensal relations -with sheep 'not sharing in the affective benefits of these relations, yet not suffering because of them either' (Gorman, 2019, p. 119).

However, our methods suggest lookering involves a distributed form of mutual (but not equal) benefit. As we have seen, on the one hand human participants express how connecting to the landscape and knowing and caring for the sheep - what we described as a sense of guardianship - provides them with a sense of wellbeing. On the other hand, the sheep undoubtedly, if temporarily, benefit from the attention of the lookerers - mending fences to keep dogs out; looking for signs of illness, reminding the public to be aware of the sheep's presence. The fact that they are involved in conservation grazing - framed as a more dispersed ecological (human?) benefit, encouraging a more biodiverse landscape - complicates the question of who benefits and how.

At the same time, it is vital to recognise that our lookering sites were not the only, and certainly not the definitive, multispecies setting as far as the sheep are concerned. Their lives incorporate time in and movement between multiple sites (farm, lorry, pen, abattoir) and practices (shearing, slaughter, reproduction, pregnancy, suckling) involving human others (farmers, drivers, slaughterhouse workers, vets). In the context of lookering, the spectre of the abattoir hangs over 
notions of care and guardianship, but was often left unarticulated by our participants, whilst for others discussion prompted by us was cut short with a discomfort that was evident. As is the case with our sheep, a focus on empirically more 'comfortable intellectual and ethical spaces' (Kopnina, 2017, p. 351) often obscures forms of violence towards nonhuman animals.

\section{Discussion}

In sum, we adopted the qualitative research methods of walking and talking, knowing and showing to explore human-animal dimensions of a voluntary shepherding (lookering) programme. Situating our interviews and observations in the lookering landscape, and in motion, helps reveal some of the dynamism and complexity involved in a form of human-animal relation rarely examined under the auspices of the animal turn to date. A brief account of some of our findings indicates how our methodological approach hints at a rich set of themes, emerging at least in part through the situated, entangled encounters of humans, sheep, other species and landscape. In terms of our research questions, lookering was experienced and understood by human participants primarily in terms of a sense of positive connection to the landscape in general and the sheep in particular. In describing shepherding, Gray uses the term 'emplacement' to describe the embodied process and sense of a person becoming embedded in place, which 'happens in the sensuous act of walking and biking over the landscape' (p. 228). Our method captured the sensuous act of walking for lookerers. Whilst not equivalent, in their own repeated visits to these particular places, combined with their attentiveness to sheep and the landscape, lookerers evoke their own sense of emplacement, a word which we feel captures some of the benefits of lookering for human participants.

Lookering also involved a sense of guardianship which indicates that as a humananimal relationship, borrowing Gorman's framework, lookering involves a degree of mutualistic benefit, for humans, sheep, and perhaps more widely for other species too if we incorporate the emphasis on conservation grazing as encouraging a more biodiverse landscape. However, in pursuing animal biographies beyond the situated encounter of lookering, answers to questions of who benefits and how become more complex and ambivalent. First, we recognize this brute fact of their wider biographies - that they remain agricultural commodities and are slaughtered for meat. Second, we recognise the asymmetry in participants' talk about the benefits of nature connection, and the sense of meaning and purpose they derive from lookering, compared to how much (or little) is said about a sheep's destiny. In response to both, we might instead reach for a reading of these relations as parasitical. In the end though, we would argue that Gorman's framework offers a valuable way of exploring the lively complexity of a variety of human-animal relations in terms of who benefits and how, without having to decide finally on defining it in terms of parasitism, commensalism or mutualism. 
As we noted at the outset, the animal turn has witnessed an explosion of different methodologies attempting to explore and interrogate human-animal and multispecies relations, and the viability of a broad range of qualitative methods for addressing human-animal and multispecies relations remains to be seen (Shapiro, 2017). Whilst a remodeled ethnography has gained the most attention and momentum, all approaches face the same thorny questions in getting at 'animals as such' and the difficulties of speaking for and with nonhuman others. Simply put, there is no methodological silver bullet,

Taking a qualitative approach to our human-sheep case study, we adopted walking and talking, knowing and showing as our chosen method, falling between the 'conventional' and the 'innovative' in Dowling et al's typology of more-than-human research methodologies. In advancing more-than-human and multispecies scholarship, we consider it essential to situate the place of encounters being studied within multiple complex spaces through which they exist. This is precisely why wider historical, material and social biographies of the species involved is so important. We conclude that our approach offers a suitable method for exploring human-animal relation and for addressing critical questions such as who benefits from these relations, and how.

\section{References}

Adams, M. (2020) Anthropocene Psychology: Being Human in a More-Than-Human World. London: Routledge.

Alam, A., McGregor, A., \& Houston, D. (2018). Photo-response: Approaching participatory photography as a more-than-human research method. Area, 50(2), 256265.

Andersson Cederholm, E., Björck, A., Jennbert, K., \& Lönngren, A. S. (Eds.) 2014 Exploring the animal turn: Human-animal relations in science, society and culture. Lundt: Lundt University Press.

Arcari, P., Probyn-Rapsey, F., \& Singer, H. (2020). Where species don't meet: Invisibilized animals, urban nature and city limits. Environment and Planning E: Nature and Space, DOI:10.1177/2514848620939870

Åsberg, C. (2018). Feminist Posthumanities in the Anthropocene: Forays into the Postnatural. Journal of Posthuman Studies, 1(2), 185-204.

Bastian, M., Jones, O., \& Moore, N. (Eds.) (2017). Participatory research in more-thanhuman worlds. New York: Taylor \& Francis. 
Castrodale, M. (2017). Mobilizing Dis/Ability Research: A Critical Discussion of Qualitative Go-Along Interviews in Practice. Qualitative Inquiry. 24(1) 45-55

Coombes, B., Johnson, J. T., \& Howitt, R. (2014). Indigenous geographies III: Methodological innovation and the unsettling of participatory research. Progress in Human Geography, 38(6), 845-854.

Coulter, K. (2018). Challenging Subjects: Towards Ethnographic Analyses of Animals. Journal for the Anthropology of North America, 21(2), 58-71.

De la Bellacasa, M. (2011). Matters of care in technoscience: Assembling neglected things. Social Studies of Science, 41(1), 85-106.

Deleuze, G., \& Guattari, F. (1987). A thousand plateaus: Capitalism and schizophrenia. London: Bloomsbury Publishing.

Despret, V., \& Meuret, M. (2016). Cosmoecological Sheep and the Arts of Living on a Damaged Planet. Environmental Humanities, 8(1), 24-36.

Dowling, R., Lloyd, K., \& Suchet-Pearson, S. (2017). Qualitative methods II: 'Morethan-human' methodologies and/in praxis. Progress in Human Geography, 41(6), 823831.

Fuentes, A. (2010). Natural cultural encounters in Bali: Monkeys, temples, tourists, and ethnoprimatology. Cultural Anthropology, 25(4), 600-624.

Gillespie, K. A. (2019). For a politicized multispecies ethnography: Reflections on a feminist geographic pedagogical experiment. Politics and Animals, 5(2019), 1-16.

Gorman, R. (2019). What's in it for the animals? Symbiotically considering 'therapeutic' human-animal relations within spaces and practices of care farming. Medical Humanities, 45(3), 313-325.

Gray, J. (2014). Hefting onto place: Intersecting lives of humans and sheep on Scottish hills landscape. Anthrozoös, 27(2), 219-234.

Hamilton, L., \& Taylor, N. (2017). Ethnography after humanism: Power, politics and method in multi-species research. London: Springer.

Haraway, D. (2003). The companion species manifesto: Dogs, people and significant otherness. Chicago: Prickly Paradigm Press. 
Haraway, D. (2008). When species meet. Minneapolis: University of Minnesota Press.

Haraway, D. (2016) Staying with the trouble. Minneapolis: University of Minnesota Press.

Heddon D (2017) 12 Con-versing: Listening, speaking, turning. In: Bastian M, Jones O, Moore N, et al. (eds) Participatory Research in More-than-Human Worlds. London: Routledge, 192-208.

Hitchings, R. and Jones, V. (2004) Living with plants and the exploration of botanical encounter within human geographic research practice. Ethics Policy and Environment 7: 3-18

Ingold, T. (2000) The Perception of the Environment: Essays in livelihood dwelling and skill. London, Routledge.

Kopnina, H. (2017). Beyond multispecies ethnography: Engaging with violence and animal rights in anthropology. Critique of anthropology, 37(3), 333-357.

Lloro-Bidart, T. (2018). A feminist posthumanist multispecies ethnography for educational studies. Educational Studies, 54(3), 253-270.

Locke, P. and Keil. P. (2015) Multispecies methodologies and human-elephant relations. Engagement: A Blog published by the Anthropology and Environment Society, 27. Oct 2015

https://aesengagement.wordpress.com/2015/10/27/multispecies-methodologiesand-human-elephantrelations/ (accessed 14 May 2021)

Maurstad, A., Davis, D., \& Cowles, S. (2013). Co-being and intra-action in horsehuman relationships: A multi-species ethnography of be(com)ing human and be(com)ing horse. Social Anthropology, 21(3), 322-335.

McLeod, K. (2014). Orientating to assembling: Qualitative inquiry for more-thanhuman worlds. International Journal of Qualitative Methods, 13(1), 377-394.

Ogden, L. A., Hall, B., \& Tanita, K. (2013). Animals, plants, people, and things: A review of multispecies ethnography. Environment \& Society, 4(1), 5-24.

Pitt, $H$. (2015). On showing and being shown plants-a guide to methods for morethan-human geography. Area, 47(1), 48-55.

Robinson, A. S. (2019). Finding healing through animal companionship in Japanese animal cafés. Medical Humanities, 45(2), 190-198. 
Shapiro, K. (2017) Human-animal studies: Fertile ground for qualitative analysis. Society of Qualitative Investigations in Psychology, May 25, 2017, Fordham University.

Shapiro, K. J. (1990). Understanding dogs through kinesthetic empathy, social construction, and history. Anthrozoös, 3(3), 184-195.

Smart, A. (2014). Critical perspectives on multispecies ethnography. Critique of Anthropology, 34(1), 3-7.

Springgay, S., \& Truman, S. E. (2017). Walking methodologies in a more-than-human world: WalkingLab. Routledge.

Swanson, H. A. (2017). Methods for multispecies anthropology: thinking with salmon otoliths and scales. Social Analysis, 61(2), 81-99.

Swanson, H. A. (2019). Multispecies Research. In P. Atkinson, S. Delamont, A. Cernat, J.W. Sakshaug, \& R.A. Williams (Eds.), SAGE Research Methods Foundations.

Taylor A and Pacini-Ketchabaw V (2015) Learning with children, ants, and worms in the Anthropocene: Towards a common world pedagogy of multispecies vulnerability. Pedagogy, Culture and Society 23(4): 507-529.

Van Dooren, T., Kirksey, E., \& Münster, U. (2016). Multispecies Studies: Cultivating Arts of Attentiveness. Environmental Humanities, 8(1), 1-23.

Wright, S., Lloyd, K., Suchet-Pearson, S., Burarrwanga, L., Tofa, M. and Country, B. (2012), Telling stories in, through and with Country: engaging with Indigenous and more-than-human methodologies at Bawaka, NE Australia, Journal of Cultural Geography, 29(1): 39-60.

\footnotetext{
${ }^{1}$ David Abram introduced the term 'more-than-human world' to refer collectively to Earthy life in a way that captures how it exceeds the human rather than simply not being human (Abram, 1996).
} 